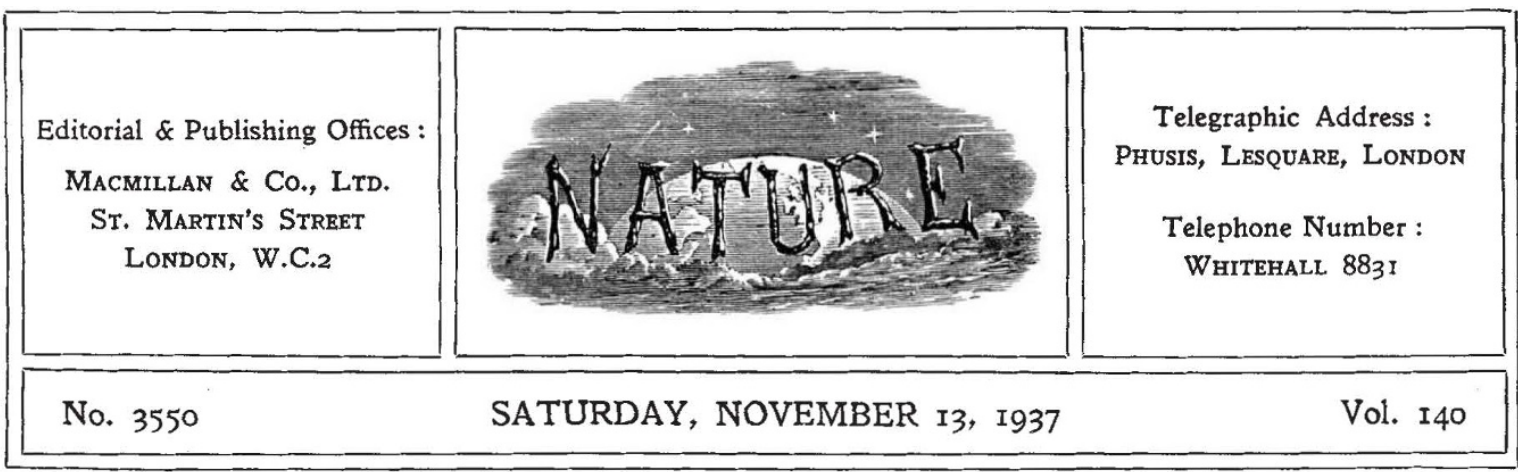

\title{
Land Drainage in England and Wales
}

$\mathrm{O}$ $\mathrm{NE}$ of the most insistent problems of recent years in the domestic legislation of Great Britain has been that of land drainage. There are many and extensive areas in England and Wales where efficient drainage is a vital necessity to the safety, health and welfare of the inhabitants. Inundations which have afflicted such districts in the past, and even now, in spite of definitely organized preventive measures, can still cause widespread devastation with loss of life and property and possible epidemics of disease, have been a source of constant and anxious concern to successive Governments. Ultimately, a Royal Commission was appointed to investigate the matter, and in 1927 its report appeared, making a series of recommendations of a striking and drastic character, which, supported by public opinion, were, after full discussion, embodied in the Land Drainage Act, 1930. Since that date, a fundamental and revolutionary change has been taking place in the drainage administration of the country; and an account of the operations and proceedings taken under the Act has recently appeared*.

The main difficulty of the situation prior to the passing of the Act was the existence of a heterogeneous collection of drainage authorities, totalling some 361, with miscellaneous constitutions, powers and jurisdictions. Moreover, these bodies, however active and well-intentioned, were inadequately provided with funds and lacked the necessary resources for coping with conditions which had naturally changed more or less fundamentally with the lapse of a long period of years since they were first instituted. Some of them, notably the so-

* Report of Operations and Proceedings under the Land Drainage Act, 1930, from the passing of that Act (1st August, 1930) to 31st March, 1937. Pp. iv +75 . (London: H. M. Stationery Office, 1937.) 1s. 6d. net. called "Commissions of Sewers" (the word "sewer" originally signified an open watercourse), dated back to a very remote epoch, and these were preceded by a body, still legally in existence, "the Lords, Bailiffs and Jurats of Romney Marsh," which has had an effective career of nearly seven hundred years. Commissions of Sewers were first appointed in the fifteenth century, but were placed on a more permanent basis by the Statute of Sewers of Henry VIII's reign (1531). Thereafter, other bodies were created, either by private Act of Parliament ad hoc, or arising out of the provisions of local inclosure awards in connexion with the inclosure of common lands, a process which was at its height in the closing years of the eighteenth and early years of the nineteenth century.

Of this complicated and cumbersomely ineffective machinery the new Land Drainage Act made a clean sweep, and it repealed all the enactments in regard to flood prevention which had been made through centuries of English history, substituting for them a properly organized and co-ordinated system of administration through authorities designated Catchment Boards, taking their title from the drainage unit adopted by the Royal Commission ; namely, the catchment area of each river, which is bounded by the natural watershed or water-parting. These catchment areas vary considerably in character, extent and rateable value. Some areas are largely agricultural, such as the Great Ouse, Rother, Severn, Wye, etc., while others include industrial regions, such as the Yorkshire Ouse, Trent, Mersey and Irwell and the mid-Glamorgan rivers. Another feature of notable contrast is the relative proportion of lowlands and uplands. In the catchment area of the Romney and Denge Marsh Main Drains, the percentage of 
lowlands is $72 \cdot 75$, while in the Bristol Avon area it is only $3 \cdot 22$.

At the outset, the Act scheduled forty-seven catchment areas-not by any means an exhaustive list, but as many as it was considered possible to deal with at the start. Provision was made for additions, and as a result of these and some amalgamations, there were at the date of the report under consideration forty-eight catchment boards in England and Wales.

The responsibilities of catchment boards are not limited to the drainage or discharge of water from their respective areas. In a number of cases they have the contingent duty of protecting the low-lying marshlands on the sea or estuary frontage from tidal flooding. Thus, in the case of the Essex Rivers Catchment Area, there are, in addition to a length of 380 miles of main river, no fewer than 320 miles of sea or estuary embankment and defences along the north bank of the Thames from the outskirts of London to Dovercourt, and these need constant supervision and repair.

The term 'main river' requires explanation. It is rather difficult to define with exactitude, though the meaning is fairly obvious. But, for the purposes of the Act, the signification has to be a little elastic. The 'main river' may include more than one channel, and, in fact, consist of several independent streams. It has not been altogether easy in some cases to decide where the main river or main channel should end, or what tributaries should be included.

The existence of tributaries and auxiliary streams has given rise to the formation, under the Act, of internal drainage boards, with duties subordinate to those of the catchment boards. Internal drainage boards can be formed for areas "capable of deriving benefit or escaping danger as a result of drainage operations," so that, in certain cases, a drainage district may exist where there is no catchment area.

The financial depression which set in almost immediately after the passing of the Act hampered, to no small extent, the initiation of important schemes of flood protection works, though a little was done where the need was urgent and perhaps desperate. Prior to March 31, 1934, only ten schemes, totalling nearly $£ 300,000$, were approved for the purpose of receiving grants out of monies provided by Parliament towards the expenditure incurred by catchment boards in respect of the improvement of existing works or the construction of new works. Of this amount, $£ 179,000$ was urgently required for sea defences in Rye Bay and north Norfolk. In the former locality, the sea actually breached the defences in November 1930, washed away a number of bungalows and left a widening gap in the natural shingle bank, which was the only defence at that point. When the financial situation eased, as it did after April 1934, fuller advantage was taken of Government assistance, and greater facilities were afforded for dealing with improvement schemes of a general character. Up to March 31 last, seventy-one such schemes had been approved, between fifty and sixty of which are still in course of execution, at an estimated outlay of upwards of six millions sterling.

Attention may appropriately be directed to a feature of the functions of catchment boards having an important bearing on a subject which has often been mentioned in these columns. We have in the past pointed out repeatedly how essential it is in the general interests of the country to institute an effective national survey covering all available water resources. After considerable pressure had been brought to bear on the Government by the British Association, jointly with the Institution of Civil Engineers, a Survey was set up a couple of years ago under the auspices of the Ministry of Health, and two annual reports of its activities have already been issued. Whatever misgivings we may have felt about the limitations apparently imposed on the Survey by its association with a department which cannot be said to be interested in the industrial and commercial use of water, the fact remains that, at present, it is the only organization existing for the purpose.

The Survey, however, cannot carry out singlehanded all the operations which it is desirable should be covered, and it will have to rely very largely on the co-operation of external organizations. The catchment boards, with their control over the main rivers in their respective areas, can make a very effective contribution to the data necessary for the Survey, by undertaking a comprehensive study of their rivers, and by installing an adequate number of gauges to record the daily flow, so as to determine the run-off under varying conditions corresponding to the incidence of the local rainfall. This is a very important matter, and we are glad to see-even if only in the final sentence of the report-that attention is directed to it in the account of work being done under the Land Drainage Act. 